\title{
Mekanisme Transisi IPv4 dan IPv6 Menggunakan Metode Automatic Tunneling Pada Jaringan Client Server Berbasis Linux
}

\author{
Imam Marzuki \\ Program Studi Teknik Elektro, Fakultas Teknik, Universitas Panca Marga \\ Jl. Yos Sudarso 107 Pabean Dringu Probolinggo 67271 \\ telp (0335) 422715, 427923 \\ Email : imam@upm.ac.id
}

\begin{abstract}
Abstrak - Alamat IP merupakan jantung sebuah jaringan komputer. Hal ini dikarenakan komputer yang terhubung ke jaringan memerlukan IP untuk saling berkomunikasi. Tanpa alamat IP, komputer tersebut tidak dapat saling bertukar data. Alamat IP yang biasa digunakan yaitu IPv4. Namun IPv4 telah digunakan lebih dari 20 tahun dan diperkirakan akan habis seiring dengan bertambahnya pengguna internet di dunia. Perkembangan dari IPv4 adalah IPv6. IPv6 menyediakan alamat IP yang jauh lebih banyak dan tidak akan habis. Dengan demikian, untuk mengatasi permasalahan IPv4 yang memiliki keterbatasan adalah menggunakan IPv6. Permasalahan muncul ketika akan mengimplementasikan IPv6. Implementasi tidak serta merta dilakukan karena secara langsung IPv6 tidak bisa melakukan interkoneksi dengan IPv4. Hal ini tentunya akan menimbulkan kesalahan pada jaringan IPv4 yang telah ada. Sebagai solusi dari masalah implementasi IPv6, maka diperlukan suatu mekanisme transisi IPv4 ke IPv6 atau sebaliknya. Tujuan pembuatan mekanisme transisi ini adalah supaya paket IPv6 dapat dilewatkan pada jaringan IPv4 yang telah ada ataupun sebaliknya. Metode yang digunakan adalah automatic tunneling. Dari hasil implementasi yang dilakukan paket IPv6 dapat dikirimkan ke jaringan IPv4 tanpa mengubah infrastruktur jaringan IPv4.
\end{abstract}

Kata kunci: alamat IP, infrastruktur IPv4, transisi

Abtract - IP address is the heart of a computer network. This is because computers connected to the network require IP to communicate with each other. Without an IP address, the computer cannot exchange data. IP address commonly used is IPv4. But IPv4 has been used for more than 20 years and is expected to run out along with the increase in internet users in the world. The development of IPv4 is IPv6. IPv6 provides a much more IP address and will not run out. Thus, to overcome IPv4 problems that have limitations is to use IPv6. Problems arise when implementing IPv6. Implementation is not necessarily done because directly IPv6 cannot interconnect with IPv4. This of course will cause errors on existing IPv4 networks. As a solution to the problem of implementing IPv6, an IPv4 transition mechanism to IPv6 is needed or vice versa. The purpose of making this transition mechanism is for IPv6 packets to be passed on existing IPv4 networks or vice versa. The method used is automatic tunneling. From the results of the implementation carried out IPv6 packages can be sent to IPv4 networks without changing the IPv4 network infrastructure.

Keywords: IP address, IPv4 infrastructure, transition

\section{PENDAHULUAN}

Teknologi Informasi dan Komunikasi berbasiskan angka 0 dan 1. Pengguna internet seperti, Facebook, Twitter, dan lain-lain adalah manipulasi angka 0 dan 1 . Manipulasi angka 0 dan 1 tersebut dinamakan alamat IP dan TCP. Alamat IP merupakan bagian dari protokol TCP/IP yang digunakan untuk pengalamatan data. Sedangkan Transmission Control Protocol (TCP), merupakan bagian dari protokol TCP/IP untuk menjamin integritas data yang dikirim. Oleh karena itu, penulisan TCP/IP selalu digandengkan.

Namun demikian alamat IP dapat dikatakan lebih penting karena pengguna tidak akan mampu merancang dan membangun sistem dan keamanan jaringan yang mumpuni seperti Local Area Network (LAN), Game Center Online, Hostpot Area, Wide Area Network (WAN), Metropolitan Area Network (MAN), Intranet, Internetwork, Sistem Informasi Online, Ticketting, Content, dan seterusnya tanpa menguasai Alamat IP.

Perangkat jaringan apapun yang digunakan dapat bekerja karena adanya alamat IP. Tanpa adanya perancangan alamat IP yang benar, semua alamat situs menjadi kacau. Misalkan ketika pengguna mengetikkan www.facebook.com tapi yang muncul www.google.com, dan lain sebagainya.

Alamat IP merupakan jantung sebuah jaringan komputer. Hal ini dikarenakan komputer yang terhubung ke jaringan memerlukan IP untuk saling berkomunikasi. Tanpa alamat IP, komputer tersebut tidak dapat saling bertukar data. Alamat IP yang biasa digunakan yaitu IPv4. Namun IPv4 telah digunakan lebih dari 20 tahun dan diperkirakan akan habis seiring dengan bertambahnya pengguna internet di dunia. Perkembangan dari IPv4 adalah IPv6. IPv6 menyediakan alamat IP yang jauh lebih banyak dan tidak akan habis. Dengan demikian, untuk mengatasi permasalahan IPv4 yang memiliki keterbatasan adalah menggunakan IPv6. Permasalahan muncul ketika akan mengimplementasikan IPv6. Implementasi tidak serta merta dilakukan karena secara langsung IPv6 tidak bisa melakukan interkoneksi dengan IPv4. Hal ini tentunya akan menimbulkan kesalahan pada jaringan IPv4 yang telah ada. 
Sebagai solusi dari masalah implementasi IPv6, maka diperlukan suatu mekanisme transisi IPv4 ke IPv6 atau sebaliknya. Tujuan pembuatan mekanisme transisi ini adalah supaya paket IPv6 dapat dilewatkan pada jaringan IPv4 yang telah ada ataupun sebaliknya.

Berdasarkan latar belakang pemilihan judul, maka yang menjadi permasalahan adalah :

1. Bagaimana merancang dan membuat mekanisme transisi IPv4 dan IPv6?

2. Bagaimana mengimplementasikan metode automatic tunneling untuk mekanisme transisi pada jaringan client server?

Batasan masalah dalam penelitian ini adalah :

1. jaringan client server yang digunakan terdiri dari 2 komputer dengan 1 switch.

2. Sistem operasi yang digunakan pada server adalah linux server. Sedangkan pada client adalah linux desktop.

3. Pada server diberikan IPv6. Sedangkan pada client diberikan IPv4.

4. Tidak melibatkan router untuk koneksi jaringan.

Tujuan penelitian ini adalah :

1. Merancang dan membuat mekanisme transisi IPv4 dan IPv6.

2. Mengimplementasikan metode automatic tunneling untuk mekanisme transisi pada jaringan client server.

Manfaat penelitian ini antara lain :

1. Mengetahui penerapan struktur bilangan desimal, biner, dan hexadesimal melalui alamat IP.

2. Mempelajari IP generasi yang akan datang atau NGN (Next Generation Network).

3. Penerapan metode ini tidak mengganggu infrastruktur jaringan yang sudah ada.

\section{TINJAUAN PUSTAKA}

\subsection{Linux : Sistem Operasi Masa Depan}

Sebenarnya yang disebut Linux adalah sebuah kernel, yang merupakan bagian paling penting dari sebuah sistem operasi, yang menangani $\mathrm{I} / \mathrm{O}$, pengaturan memori dan interaksi antara perangkat keras dengan aplikasi. Kernel Linux merupakan kernel standar yang digunakan oleh distribusi-distribusi yang ada sekarang ini.

Perbedaan yang ada antar distribusi hanyalah paketpaket aplikasi yang disertakan, sistem penyusunan direktori, init script, dan lain-lain. Semua sama baiknya, tergantung dari selera pengguna.

Linux dapat dijalankan dengan baik pada komputer yang sudah memiliki sistem operasi lain seperti Microsoft Windows, MS-DOS ataupun OS/2. Pada saat komputer dihidupkan, pengguna dapat memilih untuk menjalankan komputer tersebut dengan sistem operasi Linux atau sistem operasi lainnya. Sistem seperti ini dinamakan dual boot.

Namun bukan berarti MS-DOS, Windows atau sistem operasi lain dibutuhkan untuk menjalankan Linux. Linux adalah sistem operasi yang dapat berdiri sendiri dan tidak bergantung pada sistem operasi yang lain.

\subsection{Jaringan Komputer}

Pada zaman komputer pertama kali diciptakan, komputer masih merupakan barang yang sangat mewah, sehingga sangat jarang ada lembaga atau universitas yang memiliki komputer lebih dari satu, komputer menjadi lebih umum sehingga beberapa lembaga mulai dapat memiliki lebih dari satu komputer.

Masalah mulai timbul ketika dibutuhkan pertukaran data antara dua komputer tersebut. Pada awalnya pertukaran data antar komputer dilakukan dengan menggunakan tape, disket atau media lainnya yang dipindahkan dari satu komputer ke komputer lainnya.

Untuk memecahkan masalah tersebut, diciptakan jaringan komputer yang dapat menghubungkan satu komputer dengan komputer lainnya. Sampai saat ini jaringan komputer sudah banyak digunakan di perkantoran, kampus-kampus dan lain-lain.

Dengan adanya jaringan komputer, banyak manfaat lain yang dapat diperoleh, komputer yang berada dalam jaringan tersebut dapat berbagi pakai peralatan seperti printer, tempat penyimpanan, CD ROM dan juga softwaresoftware yang ada. Kemudian dengan adanya jaringan, data yang ada dalam jaringan tersebut dapat dijadikan satu sehingga dapat diakses secara lengkap untuk membuat sebuah keputusan. Dengan jaringan komputer, komunikasi antar pemakai komputer juga dapat dilakukan melalui email, chatting ataupun teleconference sehingga akan lebih efisien.

\subsection{Topologi Jaringan}

Topologi jaringan komputer adalah aturan bagaimana terminal-terminal dalam suatu jaringan komputer disusun. Susunan ini akan menentukan metode akses dan media pengiriman yang digunakan.

Topologi jaringan yang utama adalah Bus, Ring dan Star, masing-masing topologi tersebut memiliki kelebihan dan kekurangan masing-masing sesuai dengan kondisi yang ada. Pada prakteknya sebuah jaringan komputer nantinya dapat terdiri dari gabungan ketiga topologi tersebut.

\subsection{TCP/IP}

Seperti manusia, komputer juga membutuhkan bahasa yang sama untuk dapat berkomunikasi dengan komputer lain. Bahasa yang digunakan oleh komputer untuk berkomunikasi disebut protokol. Protokol berisi sekumpulan aturan mengenai bagaimana masing-masing komputer dalam jaringan harus berkomunikasi.

Salah satu protokol yang digunakan dalam jaringan komputer adalah TCP/IP, sebenarnya TCP/IP terdiri dari sekumpulan protokol yang berbeda. TCP/IP merupakan singkatan dari Transmission Control Protocol / Internet Protocol.

\begin{tabular}{|c|}
\hline Application layer \\
\hline Transport laver \\
\hline Network layer \\
\hline Network Interface layer \\
\hline
\end{tabular}

Gambar 1. Arsitektur TCP/IP

\subsection{Dasar Alamat IP}

Supaya data yang dikirimkan dapat mencapai tempat yang dituju, dalam jaringan komputer ada yang disebut alamat IP (Internet Protocol), seperti alamat rumah, masing-masing komputer yang terhubung dalam jaringan tersebut memilliki sebuah alamat yang unik. Contoh sebuah alamat IP adalah sebagai berikut:

\subsubsection{1}

Untuk memudahkan bagi manusia untuk membaca, alamat IP ditulis dengan format desimal seperti diatas, tetapi komputer sebenarnya melihat alamat tersebut dalam bentuk biner. Alamat diatas akan menjadi seperti berikut jika dijadikan bentuk biner: 
Empat buah angka dalam alamat IP diatas disebut dengan oktet, karena masing-masing jika diterjemahkan ke dalam biner akan berjumlah 32 digit, itu adalah ukuran dari alamat IP yaitu 32 bit.

Karena setiap oktet dapat memiliki nilai antara 0 sampai 255, alamat IP dapat bernilai mulai dari 0.0.0.0 sampai 255.255.255.255 yang jika dihitung akan dapat membuat kombinasi 4.294.967.296 alamat unik. Jumlah tersebut dikurangi dengan beberapa alamat yang digunakan untuk keperluan khusus. Jumlah itu menunjukkan berapa banyak komputer dan perangkat yang dapat terhubung satu sama lain.

\subsection{Jaringan dalam Linux}

Hampir semua distribusi Linux yang ada di pasaran menawarkan fasilitas jaringan yang sudah stabil, beberapa distribusi menyertakan beberapa tool yang membantu dalam melakukan konfigurasi jaringan sehingga menjadi lebih mudah.

Setiap mesin yang terhubung ke dalam jaringan TCP/IP (protokol utama yang digunakan dalam Linux) memiliki sebuah alamat unik yang disebut alamat IP (Internet Protocol) sehingga sebuah mesin dapat menemukan mesin lainnya dalam jaringan tersebut.

\subsection{IPv6}

IP atau Internet Protokol diciptakan untuk standar komunikasi pada jaringan komputer yang berjalan dengan sistem operasi UNIX. Saat ini IP sudah menjadi standar yang digunakan pada sistem operasi jaringan yang ada pada saat ini untuk dapat terkoneksi satu sama lain. IP yang digunakan secara luas saat ini adalah IPv4 atau IP versi 4.

Sebuah IP versi 4 memiliki panjang 4 byte (32 bit), untuk memudahkan pembacaan, IP ditulis dalam bentuk desimal dengan tiap-tiap byte dipisahkan dengan tanda titik. Satu byte tersebut disebut oktet. Perhatikan contoh sebuah alamat IP berikut:

\section{$0000101000000000 \quad 0000000000000001$}

akan ditulis menjadi:

10.0.0.1

Oleh karena setiap oktet terdiri dari 8 bit, maka setiap oktet dapat memiliki nilai antara 0 sampai 255 karena itu alamat IP dapat bernilai mulai dari 0.0.0.0 sampai 255.255.255.255 yang jika dihitung akan dapat membuat 4.294.967.296 alamat unik.

Seiring dengan perkembangan internet, peralatan yang terkoneksi ke internetpun menjadi semakin banyak. Hal ini menimbulkan masalah karena keterbatasan jumlah alamat IP di atas yang menurut para ahli sebentar lagi akan habis terpakai.

Apalagi pada masa yang akan datang, semua peralatan elektronik seperti handphone dan PDA diramalkan akan memiliki kemampuan untuk terhubung jaringan sehingga kebutuhan akan alamat IP akan menjadi jauh semakin besar.

Untuk memecahkan masalah tersebut, diciptakan IPv6 atau IP versi 6 yang saat ini mulai banyak digunakan meskipun statusnya sebagian besar masih percobaan.

Saat ini di internet berjalan dua versi IP tersebut, sebagian besar jaringan masih menggunakan IP versi 4 atau IPv4 dan beberapa jaringan yang digunakan untuk percobaan mulai menggunakan IPv6, tetapi peralihannya dilakukan secara bertahap.

IPv6 memiliki panjang 16 byte (128 bit) sehingga dapat memiliki jumlah alamat IP sampai dengan
340.282.366.920.938.463.463.374.607.431.768.211.456.

Alamat IPv6 secara umum ditulis dengan bentuk sebagai berikut:

hhhh:hhhh:hhhh:hhhh:hhhh:hhhh:hhhh:hhhh

Dalam format diatas, setiap byte dipisahkan oleh tanda titik dua dan masing-masing byte terdiri dari angka hexadesimal, sebuah contoh format alamat IPv6 adalah sebagai berikut:

E3D7:0000:0000:0000:51F4:9BC8:C0A8:6420

Dalam IPv6 byte yang bernilai nol dapat dipersingkat dengan menghilangkannya sehingga alamat di atas dapat ditulis menjadi:

E3D7:51F4:9BC8:C0A8:6420

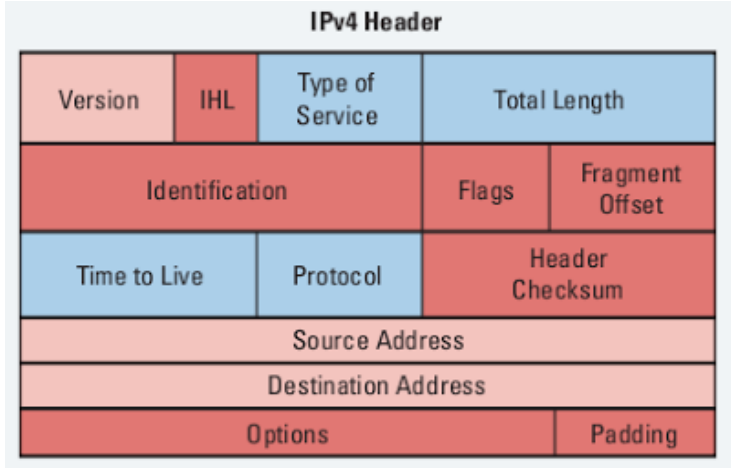

Gambar 2 Header IPv4

\begin{tabular}{|c|c|c|}
\hline Version & Traffic class & \multicolumn{2}{|c|}{ Flow label } \\
\hline Payload length & Next header & Hop limit \\
\hline & Source address \\
\hline & \\
& Destination address \\
&
\end{tabular}

Gambar 3. Header IPv6

\subsection{Mekanisme Transisi}

Mekanisme transisi secara umum didefinisikan sebagai sekumpulan teknik yang dapat diimplementasikan oleh node IPv6 untuk dapat kompatibel dengan node IPv4 yang sudah eksis sebelumnya. Berikut adalah beberapa mekanisme yang dikembangkan untuk Interkoneksi dari IPv4 ke IPv6.

\subsection{Tunneling}

Tunneling digunakan untuk membangun jaringan IPv6 dengan memanfaatkan infrastruktur jaringan IPv4 yang sudah ada.Tunneling sering juga disebut enkapsulasi.

Dengan metode ini protokol IPv6 akan dienkapsulasi pada protokol IPv4. Paket yang terenkapsulasi ini kemudian di teruskan melalui jaringan IPv4 melalui infrastruktur jaringan IPv4.

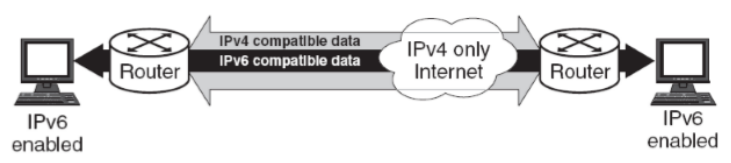

Gambar 4. Tunneling 
Pengimplentasian di Tunneling secara umum terbagi dua yaitu sebagai berikut :

\section{a. Manual Tunneling}

Manual Tunneling merupakan teknik tunneling yang mana interface tunnel dapat dikonfigurasi ekspelisit baik oleh administrator jaringan nya maupun memakai Tunnel broker. Manual Tunneling mudah untuk diimpementasikan namun pada suatu jaringan namun keterbatasan pada sisi keamanannya. Selain itu teknik sangat ketergantungan pada administrator untuk mengkonfigurasi ketika ada perubahan topologi jaringan.

\section{b. Automatic Tunneling}

Pada Automatic Tunneling interface tunnel memperoleh alamat atau prefix IPv6 berdasarkan fotmat alamat IPv4 yang telah sesuai dengan konfigurasi networknya, artinya prefix alamat IPv6 merupakan identitas unik yang dapat diperoleh dengan cara penintergrasian alamat IPv4 dengan mengubah format bilangan biner ke bilangan hexadecimal. Berikut ini salah satu Automatic Tunneling yaitu 6to4 merupakan salah satu tunneling yang membolehkan IPv6 yang boleh melewati IPv4 dengan melakukan enskapsulasi dan deskapsulasi paket. Jenis tunneling ini dapat digunakan pada individual host maupun local IPv6 network. Pada automatic 6to4, interface tunnel harus memiliki alamat IPv6, prefix di 6to4 telah dialokasikan khusus 2002::/16 untuk keperluan tunneling dan tidak pernah digunakan untuk global unicast address.

\section{METODE}

\subsection{Tahapan Penelitian}

Tahapan penelitian dalam penelitian ini antara lain:

1. Analisis masalah

Pada tahap ini analisis bertujuan mengetahui kegunaan dari sistem yang akan dibuat. Analisis dimulai dengan observasi terhadap jaringan yang telah ada kemudian dilanjutkan dengan studi literatur.

2. Perancangan Sistem

Tahap ini adalah menentukan diagram topologi dari komputer-komputer yang saling terkoneksi dan mekanisme pengiriman data dari IPv4 ke IPv6 maupun sebaliknya.

3. Implementasi

Tahap ini adalah mewujudkan apa yang sudah

direncanakan pada tahap perancangan sistem.

4. Pengujian

Tahap ini bertujuan untuk memastikan hasil implementasi sesuai dengan yang diharapkan.

\subsection{Gambaran Umum}

Pada penelitian ini, menggunakan mekanisme automatic tunneling yang berfungsi untuk melewatkan paket IPv6 melalui jaringan IPv4 yang telah ada, tanpa mengubah infrastruktur jaringan IPv4. Mekanisme automatic tunneling mempuyai prinsip kerja mengenkapsulasi paket IPv6 dengan header IPv4, kemudian paket tersebut langsung dikirimkan ke jaringan IPv4.

\subsection{Diagram Topologi Jaringan}

Pada penelitian ini diterapkan pada jaringan client server yang hanya terdiri dari dua komputer yang saling terhubung menggunakan kabel jaringan. Komputer pertama bertindak sebagai server. Server di install sistem operasi linux server dan dikonfigurasi IPv6. Sedangkan komputer kedua bertindak sebagai client. Client menggunakan sistem operasi linux desktop dan telah di konfigurasi IPv4. Client diharapkan dapat merepresentasikan jaringan IPv4 yang telah ada.

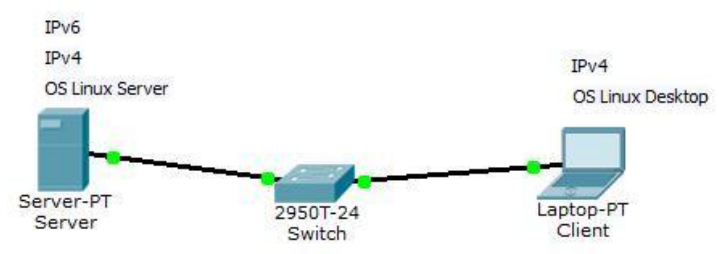

Gambar 6. Diagram topologi

\subsection{Flowchart Mekanisme Transisi IPv4 dan IPv6}

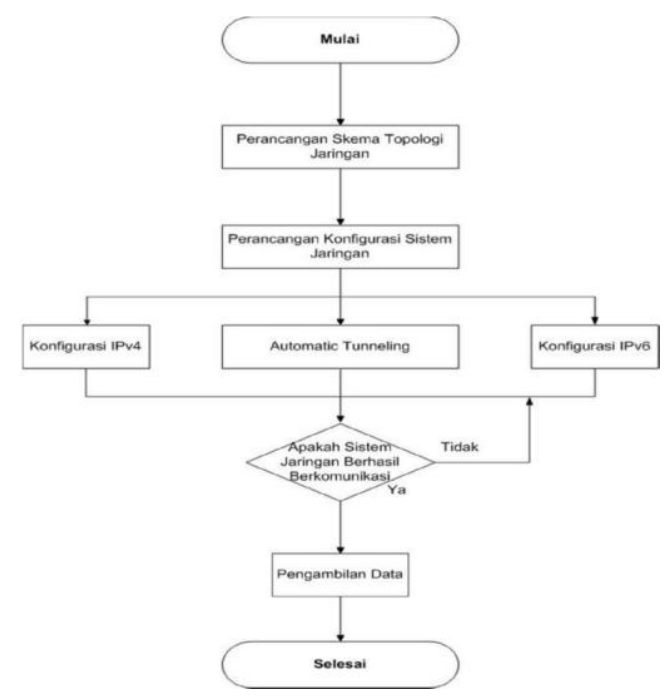

Gambar 6. Flowchart Mekanisme Transisis IPv 4 dan IPv6

\section{HASIL DAN PEMBAHASAN}

\subsection{Implementasi}

Sistem yang dibangun berada di lingkungan sistem operasi linux. Pada penelitian ini konfigurasi terhadap sistem dilakukan melalui terminal console yang berbasis text seperti halnya command prompt pada windows. Terdapat dua user yang mengakses sistem yaitu user biasa dan user root. User biasa tidak memiliki hak akses penuh terhadap sistem, salah satunya yaitu tidak bisa mengonfigurasi alamat IP. User root memiliki hak akses penuh terhadap sistem. User root inilah yang digunakan dalam penelitian ini. User biasa dan user root ditandai dengan tanda yang mengikuti sebuah direktori. Tanda \$ menandakan yang aktif pada saat ini adalah user biasa. Sedangkan tanda \# menandakan yang aktif pada saat ini adalah user root.

\subsection{Pengujian}

Pada migrasi penggunaan alamat dari IPv4 dan IPv6 di asumsikan digunakan OS Linux yang telah mendukung 2 sistem pengalamat, yaitu IPv4 dan IPv6. Langka pertama dari implementasi tersebut adalah dengan melakukan hubungan komputer menggunakan alamat IPv4 terlebih dahulu untuk mengingat kembali bagaimana cara melakukan hubungan komputer menggunakan IPv4 
tersebut berhasil, kemudian dilakukan pengimplementasian alamat IPv6 pada komputer .

\subsection{Merubah User Biasa Ke User Root}

Sebelum menggunakan super user kita harus buka terlebih dahulu yaitu terminal, tekan $\mathrm{ctrl}+\mathrm{shift}+\mathrm{t}$

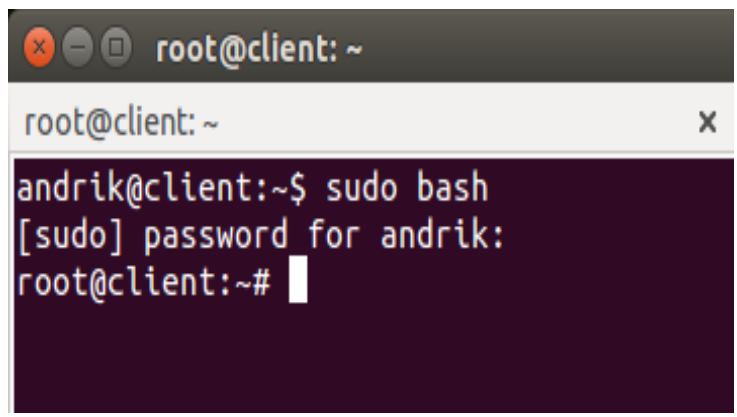

Gambar 7. Merubah User Biasa Ke User Root

Untuk mengubah User Biasa ke User Root kita lebih dahulu mengetik "sudo bash" supaya user yang diinginkan ganti menjadi User Root.

\subsection{Perubahan Alamat IPv4}

\section{ronotnclienti $\#$ ifconfin etho 192.168.9.2 netmask 255.255.255. A}

Gambar 8. Perubahan Alamat IPv4

Pada perintah perubahan alamat IPv4 tersebut, dimasukkan alamat IPv4 baru dengan alamat 192.168.0.2 serta subnet 255.255.255.0 karena menggunakan kelas $\mathrm{C}$ pada suatu interface bernama eth0.

\subsection{IPv4 Ping}

Untuk melakukan pengetesan apakah komputer 2 (Client) dan komputer 1 (Server) terhubung dengan menggunakan IPv4, maka dapat dilakukan pengecekan dengan menggunakan program kecil, yaitu program ping. Adapun perintah untuk melakukan pengecekan hubungan antara kedua komputer tersebut adalah sebagai berikut :

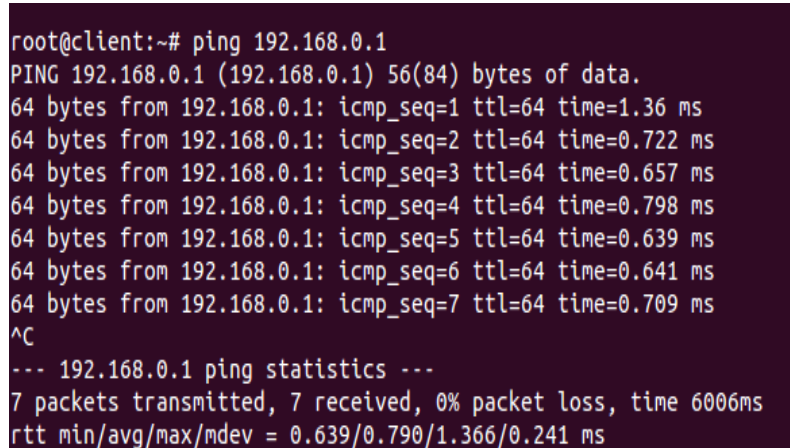

Gambar 9. Ping Komputer 2 (Client)

Dengan menggunakan perintah tersebut, maka komputer 2 (Client) dengan alamat IPv4 192.168.0.2 akan melakukan pengetan hubungan dengan komputer 1 (Server) dengan alamat IPv4 192.168.0.1. Maka untuk pengetesan komputer 1 (Server) dapat dilakukan perintah yang sama pada komputer 2 (Client).

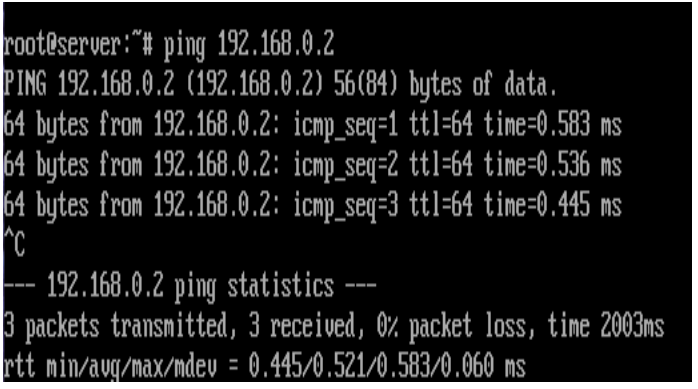

Gambar 10. Ping Komputer 1 (Server)

\subsection{Meremot Server/SSH Server}

Server yang anda akses sebagai bagian dari proses client tanpa membuka konensi terpisah, berbeda, ataupun langsung. SQL Server mengatur komunikasi antar server menggunakan RPC. SQL Server yang client terkoneksi oleh client yang bersangkutan membuka koneksi lain ke remot server dan mengajukan permintaan stored procedure ke remote server.

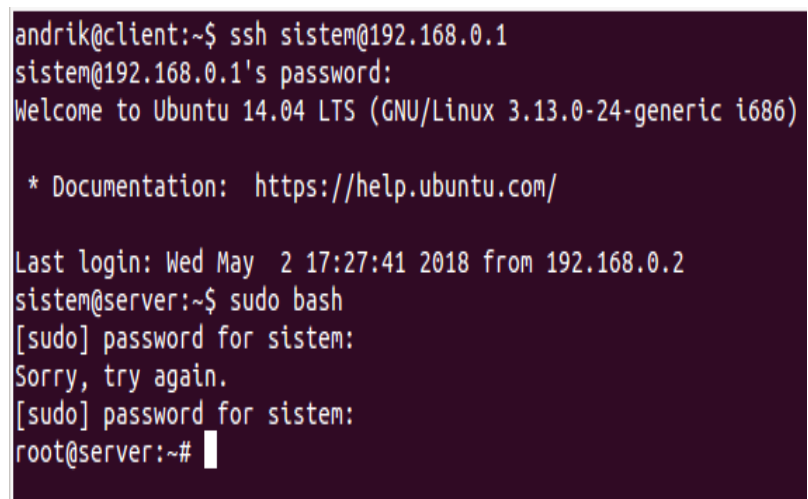

Gambar 11. Meremote Server/SSH Server

\subsection{Cek IP Hasil Interkoneksi IPv6 dan IPv4 Komputer 1 (Server)}

Dengan menggunakan perintah di atas, maka tunneling IPv6 dalam jaringan IPv4 telah diaktifkan. Uuntuk lebih jelasnya dpat dilihat dengan menggunakan perintah "ifconfig" sebagai berikut :

\section{rootaserver: \# ifconfig sito up root@server: \# ifconfig}

Gambar 12. Cek IP Interkoneksi IPv6 dan IPv4 Komputer 1 (Server)

Hasil daripengecekan IP Interkoneksi IPv6 dan IPv4 maka menghasilkan seperti berikut :

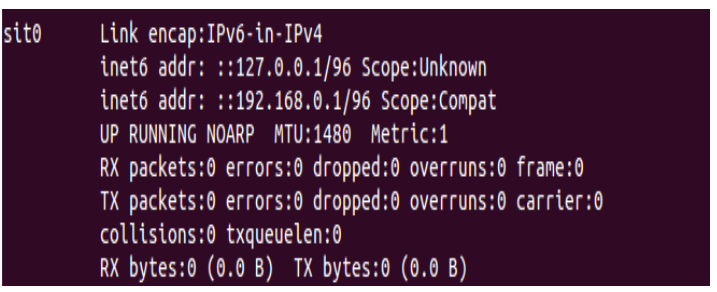

Gambar 13. Hasil IP Interkoneksi IPv6 dan IPv4 Komputer 1 (Server) 


\subsection{IPv6 Ping}

Program ini biasanya termasuk didalam paket iputils, yang didesain untuk melakukan pengetesan hubungan dengan cara mengirimkan paket Internet Control Message Protocol ICMPv6 echo request dan menunggu balasan paket ICMPv6 echo reply. Apabila koneksi berjalan baik, maka program ping6 ini akan menampilkan waktu dari proses pengiriman paket ke tempat tujuan sampai dengan paket tersebut diterima kembali ke komputer pengirim. Untuk format perintah dari program ping6 dapat dilihat sebagai berikut :

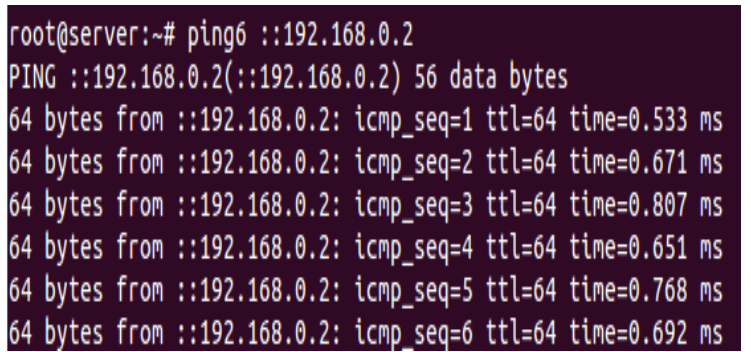

Gambar 14. Hasil ping6 komputer 1 (Server) untuk komputer 2 (Client)

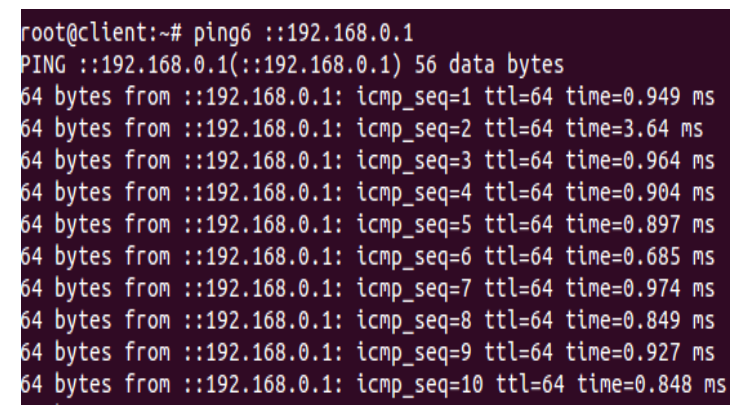

Gambar 15. Hasil ping6 komputer 2 (Client) untuk komputer 1 (Server)

\section{SIMPULAN}

Suatu rancangan harus memulai konfigurasi sistem jaringan baik hardware maupun software dan mekanisme transisi ini supaya paket IPv6 dapat dilewatkan pada jaringan IPv4 yang telah ada ataupun sebaliknya. Automatic Tunneling memperoleh alamat atau prifex IPv6 berdasarkan format alamat IPv4 yang telah sesuai dengan konfigurasi network, prifex yang dimaksud alamat IPv6 merupakan indentitas unik yang dapat diperoleh dengan cara penintegrasian alamat IPv4 dengan mengubah format bilangan biner ke bilangan hexadecimal. Perlu dilakukan penelitian yang lebih mendalam tentang transisi IPv4 dan IPv6 sehingga dapat mempermudah dalam melakukan transisi IPv4 dan mengetahui aplikasi-aplikasi apa saja yang sudah mendukung IPv6 sehingga dapat diterapkan kedalaman jaringan secara lebih luas dan berbasis IPv6.

\section{DAFTAR PUSTAKA}

(1) Fathullah, M., Purwanto, Y., dan Mulyana, A., 2012. Implementasi dan Analisis Interkoneksi IPv6 IPv4 Dengan Mekanisme Automatic dan Configured Tunneling Pada Aplikasi HTTP dan Video Streaming. Bandung
(2) Hijrih, H. 2011. Analisis Mekanisme Transisi dan Komunikasi IPv4 Dengan Ipv6 Pada Jaringan End To End. Yogyakarta

(3) Syafrizal, M., Qamar, S., dan Aji, B.D. 2013. Implementasi Migrasi IPv4 ke IPv6. Yogyakarta

(4) Saputra, E.M., Kumalasari N.E., dan Triyono, J. 2016. Pengujian Kinerja Komunikasi Data Menggunakan IPv4 vs IPv6 Pada Jaringan Clien Server. Yogyakarta

(5) Syukur, A. 2015. Perancangan dan Implementasi Internet Protocol Version 6 (IPv6) Pada Jaringan Komputer SMA Negeri 1 Pekanbaru. Pekanbaru

(6) Sugeng, W., Putri, D.T. 2015. "Jaringan Komputer Dengan TCP/IP”. Bandung : Modula

(7) Warman, I., Nugraha, S.Y.M. 2017. Analisa Implementasi Interkoneksi Antara IPv4 Dengan IPv6 Menggunakan Metode Dual Stack Pada Mikrotik Routeros. Padang 